\title{
Successful treatment with ketoconazole of Cushing's syndrome in pregnancy
}

\author{
J.A. Amado ${ }^{1}$, C. Pesquera ${ }^{1}$, E.M. Gonzalez ${ }^{1}$, M. Otero' ${ }^{1}$, J. Freijanes ${ }^{1}$ and \\ A. Alvarez \\ ${ }^{1}$ Endocrine Unit and ${ }^{2}$ Department of Obstetrics and Gynecology, Valdecilla Hospital, University of \\ Cantabria, 39008 Santander, Spain.
}

\begin{abstract}
Summary: Patients with Cushing's syndrome rarely become pregnant. This is a high risk situation both for the fetus and the mother, if untreated. We report a patient with Cushing's syndrome due to adrenocortical adenoma who became pregnant and was successfully treated with ketoconazole during the last period of pregnancy.
\end{abstract}

\section{Introduction}

Patients with Cushing's syndrome rarely become pregnant. In fact, no more than 60 cases of this association have been reported. ${ }^{1-6}$ This is a highrisk situation, both for the fetus and the mother if untreated. ${ }^{1,3,7}$ Different types of medical and surgical therapies have been used, though the experience with the various treatments is very small. We report a patient with Cushing's syndrome due to adrenocortical adenoma who became pregnant and was successfully treated with ketoconazole during the last 5 weeks of pregnancy. To the best of our knowledge this drug has not been previously tried for Cushing's syndrome in pregnancy.

\section{Case report}

A 36 year old female was referred to our unit for study of a possible Cushing's syndrome. In the last year she had developed increase in weight $(10 \mathrm{~kg})$, arterial hypertension, mild hirsutism, facial plethora, easy bruising and generalized weakness. She had been taking oral contraceptive pills, but a month before consultation had stopped them. Before taking the pills she had had normal menses, two successful pregnancies and one spontaneous abortion.

On examination she had central obesity (height $1.50 \mathrm{~m}$, weight $70 \mathrm{~kg}$ ), with a round red face and buffalo hump. Facial hirsutism and arterial hypertension $(160 / 95 \mathrm{mmHg}$ ) were found. An oral glucose tolerance test with $75 \mathrm{~g}$ was indeterminate. Plasma cortisol (RIA Amerlex kit, Amersham, UK) at $08.00 \mathrm{~h}$ was $772 \mathrm{nmol} / \mathrm{l}$ and at $20.00 \mathrm{~h}$

Correspondence: J.A. Amado, M.D.

Accepted: 5 September 1989
$1020 \mathrm{nmol} / \mathrm{l}$ (normal values: less than $750 \mathrm{nmol} / \mathrm{l}$ ). Free urinary cortisol excretion (RIA Amerlex kit, Amersham, UK) on two consecutive days was 1087 and $1959 \mathrm{nmol} /$ day (normal values: less than $331 \mathrm{nmol} /$ day). Urinary 17-hydroxycorticosteroids (Silber and Porter) excretion was 42.2 and $29.2 \mu \mathrm{mol} /$ day (normal values: less than $28 \mu \mathrm{mol} /$ day). Urinary 17 ketosteroids (Zimmerman) excretion was 38.8 and $25.3 \mu \mathrm{mol} /$ day (normal values: less than $37 \mu \mathrm{mol} /$ day). Plasma ACTH (RIA Immunonuclear, Stillwater, MN, USA) was 9.4 and $10.6 \mathrm{pmol} / \mathrm{l}$ at $08.00 \mathrm{~h}$ on two separate occasions (normal values: less than $22 \mathrm{pmol} / \mathrm{l}$ ). No further studies could be done.

Six weeks later a pregnancy test was positive. Routine obstetric examinations and uterine ultrasound scans were performed every two weeks. At the 9th week diabetes mellitus was noted and insulin therapy was started. With increasing doses of insulin an acceptable glycaemic control was achieved throughout the pregnancy. At the 17th week an amniocentesis was performed and a $46 \mathrm{XX}$ kariotype was found. During the course of pregnancy the patient developed an increase in weight (16 kg up to the 31 st week) and facial plethora, purplish abdominal striae, easy bruising, malleolar oedema, worsening of hypertension and muscular atrophy. Despite intensive therapy (rest, diet, diuretics, antihypertensives) clinical deterioration was noted due to sustained hypercortisolism. An ultrasound scan of the adrenal glands was technically difficult on two different occasions and definitive conclusions were not obtained. A pattern of slow fetal growth was seen.

After discussing with the patient the different therapeutic options, oral ketoconazole $(\mathrm{KCZ})$ therapy $(200 \mathrm{mg} / 8$ hours) was began at the $32 \mathrm{nd}$ week. Clinical status improved quickly (disap- 
pearance of oedema, with a loss of $7.5 \mathrm{~kg}$ in the following 5 weeks, easy control of hypertension only with diet, and improvement in muscular strength), while no evidence of adrenal insufficiency was found. Table I summarizes the hormonal responses to $\mathrm{KCZ}$. Hormonal determinations were made at $08.30 \mathrm{~h}$ using methods previously reported. ${ }^{8}$ Fetal well being was intensively checked. This therapy was maintained until the 37th week, when, after assessment of fetal lung maturation, an elective caesarean section was performed. $\mathrm{KCZ}$ was given for the last time 36 hours before surgery. The infant was a normally formed female (weight $2.080 \mathrm{~g}$ ) whose Apgar scores were 9 and 9 at 1 and 5 minutes respectively. Neither clinical nor biochemical evidence of adrenal insufficiency was found in the newborn (basal cortisol $306 \mathrm{nmol} / \mathrm{l}$, ACTH $8.1 \mathrm{pmol} / \mathrm{l}$ ). The mother's postpartum course was uneventful and insulin therapy could be stopped due to normalization of glucose levels. Mother and child were eventually discharged from hospital 13 days after delivery. In the last follow-up (18 month) the baby was growing normally.

Several months later she was again reevaluated, while not receiving medication. Plasma cortisol was again elevated at $797.3 \mathrm{nmol} / 1(08.00 \mathrm{~h})$. Urinary free cortisol excretion was $1056.7 \mathrm{nmol} /$ day, and was not suppressed by oral administration of $2 \mathrm{mg}$ dexamethasone 6-hourly for 48 hours (1172.6 nmol/day). Computerized tomography (CT) of the abdomen and ${ }^{131}$ I-iodocholesterol scan of the adrenal glands demonstrated the presence of a right adrenal adenoma, that was removed surgically without postoperative problems.

Table I Hormonal responses to ketoconazole (KCZ)

\begin{tabular}{llcc}
\hline & $\begin{array}{c}\text { Before } \\
\text { taking } \\
K C Z\end{array}$ & $\begin{array}{c}7 \text { days } \\
\text { after } \\
K C Z\end{array}$ & $\begin{array}{c}\text { Caesarean } \\
\text { section } \\
\text { day }\end{array}$ \\
\hline $\begin{array}{l}\text { Urine } \\
\text { free urinary } \\
\text { cortisol (nmol/d) }\end{array}$ & 4355 & 887 & - \\
$\begin{array}{l}\text { Plasma } \\
\text { cortisol (nmol/l) }\end{array}$ & 807 & 547 & 983 \\
$\begin{array}{l}\text { ACTH (pmol/l) } \\
\text { 11-deoxy cortisol } \\
\text { (nmol/l) }\end{array}$ & 104 & 322 & 203 \\
$\begin{array}{l}\text { aldosterone } \\
\text { (pmol/l) }\end{array}$ & 579 & 324 & 1463 \\
$\begin{array}{l}\text { oestradiol } \\
\text { (nmol/l) }\end{array}$ & $>5$ & $>5$ & $>5$ \\
$\begin{array}{l}\text { progesterone } \\
\text { (nmol/l) }\end{array}$ & $>100$ & $>100$ & $>100$ \\
\hline
\end{tabular}

\section{Discussion}

Up to now only about 60 cases of Cushing's syndrome and pregnancy have been reported..$^{1-6}$ Though endogenous hypercortisolism is much more frequent in women than in men, and is relatively frequent in fertile ages, patients with active Cushing's syndrome rarely become pregnant, because usually they have a chronic anovulation state. Patients with Cushing's syndrome and pregnancy more frequently have primary adrenal than hypothalamic-hypophyseal disease, as in our case, probably because fertility is less disturbed in this situation. It has been suggested that in primary adrenal hypercortisolism the excessive extraglandular production of oestrogens from adrenal androgens causes an inappropriate acyclic feedback signal. In Cushing's disease another mechanism may be added, i.e. loss of pulsatile luteinising hormone releasing hormone (LHRH) secretion, due to a central effect of corticotrophin releasing hormone (CRH) and/or aberration of serotoninergic activity.

Diagnosis of Cushing's syndrome in pregnancy is difficult since during normal pregnancy there is a progressive increase of plasma cortisol and ACTH as well as a raised level of free urinary cortisol in the last weeks, and a poor suppression of plasma cortisol to exogenous corticoids is found. Furthermore CT-scanning of the abdomen causes considerable irradiation of the fetus and it must be avoided. In our case the diagnosis of hypercortisolism was made before pregnancy, but we could not establish the origin of the disease until after delivery, as in other cases.

The association of Cushing's syndrome and pregnancy is a high risk situation both for the mother (diabetes mellitus, arterial hypertension, pre-eclampsia, severe myopathy, increased risk of infections and poor wound healing) and the fetus (fetal losses, stillbirths, prematurity and neonatal deaths), if untreated. ${ }^{1-7}$

As Casson et al. point out, ${ }^{6}$ intervention during pregnancy aimed at treating hypercortisolism improves its outcome. Different types of treatments have been used in this condition, depending on the origin of hypercortisolism. In the great majority of cases adrenal surgery has been used, but this approach is not devoid of risks. One case of Cushing's disease was treated with hypophyseal radiotherapy in the first weeks of pregnancy while another was managed with transsphenoidal adenectomy, though arterial hypertension was not controlled and the baby was born in very poor condition, weighing $1.300 \mathrm{~kg}{ }^{6}$ Metyrapone has been tried in two occasions, and in one patient it was associated with severe pre-eclampsia. ${ }^{3,4}$ An excess of deoxycorticosterone due to 11 beta hydroxylase inhibition was incriminated in the 
worsening of hypertension in this patient. ${ }^{4}$

Since the antifungal imadazole derivative ketoconazole inhibits cortisol production, it has been used clinically as a palliative treatment of Cushing's syndrome of different aetiologies. ${ }^{9}$ It blocks several enzymes in adrenal and testicular steroidogenesis (11 beta hydroxylase, 17 alpha hydroxylase and cholesterol side-chain cleavage). Due to the poor clinical condition of our patient we decided to use $\mathrm{KCZ}$ in the last 5 weeks of pregnancy, obtaining an impressive clinical outcome. Biochemically we found a decrease in cortisol and aldosterone levels, and an increase in 11 deoxycortisol, as expected, while oestradiol and progesterone remained elevated.

It is known that in rats $\mathrm{KCZ}$ crosses the placental barrier poorly, ${ }^{10}$ but when we considered using $\mathrm{KCZ}$ in pregnancy we were concerned about several questions. Is $\mathrm{KCZ}$ teratogenic? There is no information about this in humans, but we used it in the third trimester of pregnancy when organogenesis was ended. Does KCZ influence sexual differentiation? If $\mathrm{KCZ}$ passes through the placental barrier, a decrease in androgens during the first trimester in the male fetus could result in ambiguous external genitalia and in the next months could be associated with microphallus and/or cryptor-

\section{References}

1. Koerter, J.M., Morales, W.J., Washington, III, S.R. \& Castaldo, T.W. Cushing's syndrome in pregnancy: a case report and literature review. Am J Obstet Gynecol 1986, 154: 626-628.

2. Liu, L., Jaffe, R., Borowski, G.D. \& Rose, L.I. Exacerbation of Cushing's syndrome during pregnancy. Am J Obstet Gynecol 1983, 145: 110-111.

3. Gormley, M.J.J., Hadden, D.R., Kennedy, T.L., Montgomery, D.A.D., Murnaghan, G.A. \& Sheridan, B. Cushing's syndrome in pregnancy-treatment with metyrapone. Clin Endocrinol 1982, 16: 283-293.

4. Connell, J.M.C., Cordiner, J., Davies, D.L., Fraser, R., Frier, B.M. \& McPherson, S.G. Pregnancy complicated by Cushing's syndrome: potential hazard of metyrapone therapy. Case report. Br J Obstet Gynaecol 1985, 92: 1192-1195.

5. Bevan, J.S., Gough, H., Gillmer, M.D.G. \& Burke, C.W. Cushing's syndrome in pregnancy: the timing of definitive treatment. Clin Endocrinol 1987, 27: 225-233. chidism. In our case we knew that the fetus was a female, so, no effects on her sexual differentiation could be anticipated. Does KCZ influence the hormonal milieu of pregnancy? We could not find information about this point, but in this patient pregnancy followed its normal course. Does $\mathrm{KCZ}$ influence fetal lung maturation through an inhibition in glucocorticoid synthesis? Again we could not find data in the literature, but before delivery we demonstrated a normal maturation in our baby. Does $\mathrm{KCZ}$ induce adrenal insufficiency in the newborn? In our case we stopped $\mathrm{KCZ}$ before delivery, and neither clinical nor biochemical evidence of adrenal insufficiency was found.

We consider that low dose $\mathrm{KCZ}$ may be used as a therapy during the last period of pregnancy in Cushing's syndrome if the clinical course deteriorates and the fetus is a female, though further studies are clearly needed.

\section{Acknowledgements}

We are grateful to Dr D. Casanova who performed the adrenal operation, and to Mr J.J. Lopez-Cordovilla, Ms B. Paule, Ms C. Rentería and Ms P. Cao, who provided technical assistance.
6. Casson, I.F., Davis, J.C., Jeffreys, R.V., Silas, J.H., Williams, J. \& Belchetz, P.E. Successful management of Cushing's disease during pregnancy by transsphenoidal adenectomy. Clin Endocrinol 1987, 27: 423-428.

7. Mazor, M., Leiberman, J.R., Korenblum, R. \& Katz, M. Pregnancy complicated by Cushing's syndrome. Arch Gynecol Obstet 1987, 241: 191-193.

8. Diago, M.C., Amado, J.A., Otero, M. \& Lopez-Cordovilla, J.J. Antiadrenal action of a subanesthetic dose of etomidate. Anaesthesia 1988, 43: 641-642.

9. Sonino, N. The use of ketoconazole as an inhibitor of steroid production. $N$ Engl J Med 1987, 317: 812-817.

10. Heel, R.C., Brogden, R.N., Carmine, A., Morley, P.A., Spreight, T.M. \& Avery, G.S. Ketoconazole: a review of its therapeutic efficacy in superficial and systemic fungal infections. Drugs 1982, 23: 1-36. 